\title{
Renal failure during chemotherapy: renal biopsy for assessing subacute nephrotoxicity of pemetrexed
}

\author{
Maureen Assayag ${ }^{1 *}$, Philippe Rouvier ${ }^{1}$, Marion Gauthier ${ }^{1}$, Ghania Costel ${ }^{2}$, Philippe Cluzel ${ }^{1}$, Lucile Mercadal ${ }^{1}$, \\ Gilbert Deray ${ }^{1}$ and Corinne Isnard Bagnis ${ }^{1}$
}

\begin{abstract}
Background: Pemetrexed, a multitargeted antifolate cytotoxic agent, is currently used primarily in combination with cisplatin for metastatic non-small cell lung cancer and for malignant mesothelioma. Acute renal toxicity of pemetrexed has been recently described with polychemotherapy, in which the individual responsibility of each drug is difficult to establish. Only one recent report documents renal involvement in long-term exposed patients.

Case presentation: We report on a case of rapidly progressive nephropathy leading to the cessation of platinum salts and the secondary interruption of pemetrexed and bevacizumab. Acute tubular necrosis shown on the renal biopsy could potentially be due to pemetrexed. Persistent severe renal failure after the resumption of all drugs led to new treatment lines with gemcitabine (while the glomerular filtration rate was below $30 \mathrm{ml} / \mathrm{min} / 1.73 \mathrm{~m}^{2}$ ), then followed by Taxol.

Conclusions: The optimal strategy with regard to renal complications in cancer patients is not clear. Acute or chronic loss in renal function generally leads to a new treatment line, possibly impairing the overall success of the treatment. The use of chemotherapy in patients with a glomerular filtration rate below $30 \mathrm{ml} / \mathrm{min} / 1.73 \mathrm{~m}^{2}$ is usually associated with an increased risk of side effects when not contraindicated by renal elimination of the drug.
\end{abstract}

\section{Background}

Most cancer patients receive polychemotherapy. The anticipated efficacy may only be attained, however, if the regular protocol is conducted in its entirety. Renal failure usually leads to delayed or interrupted chemotherapy, and in the absence of full treatment, the expected benefits may be elusive. Alternatively, second- or third-line treatment is offered if drugs are manageable with the maintenance of a low glomerular filtration rate (GFR).

As shown in several studies [1], renal failure appears therefore to be one of the main causes for chemotherapy discontinuation. Indeed, individual compliance with the use of drugs in polychemotherapy regimens is usually difficult to confirm. The reversibility of acute renal events determines whether

\footnotetext{
* Correspondence: Maureen.assayag@gmail.com

'Pitié Salpêtrière Hospital, 75013 Paris, France

Full list of author information is available at the end of the article
}

a strategy can be followed, since many drugs cannot be prescribed in case of severe renal failure. Prevention measures, rapid diagnoses and extensive workups to determine the causes of GFR decline are necessary and are urgently required before stage 4 or 5 occurs, in which case irreversibility would prevent any future cancer therapy.

Anticancer drugs may exhibit different forms of renal toxicity (namely tubular, interstitial, glomerular or vascular), and often only renal biopsy can shed light on the mechanism of renal function decline. We describe a typical case of a cancer patient treated with 3 different drugs exhibiting severe renal failure. We emphasize the therapeutic changes that were necessary due to non-reversible renal failure and question the potential consequences on the outcome. We also discuss the benefits of renal biopsy in helping to diagnose drug-induced renal toxicity. 


\section{Case presentation}

A 66-year-old woman was admitted in March 2015 to Pitié Salpêtrière Hospital for rapidly progressive kidney failure. TNM stage IV lung adenocarcinoma had been diagnosed in December 2013 with pleural and nodal metastasis. Treatment began in January 2014 with three sessions of external radiotherapy and six sessions of chemotherapy with cisplatin $\left(75 \mathrm{mg} / \mathrm{m}^{2}\right)$, pemetrexed $\left(500 \mathrm{mg} / \mathrm{m}^{2}\right)$ and bevacizumab $(10 \mathrm{mg} / \mathrm{kg})$. Her only other past medical history was dyslipidemia. She had no diabetes and no hypertension. Before beginning chemotherapy, her plasma creatinine level was $50 \mu \mathrm{mol} / \mathrm{L}$, corresponding to an estimated GFR (eGFR) of $113 \mathrm{ml} / \mathrm{min} /$ $1.73 \mathrm{~m}^{2}$ using the simplified Modification of Diet in Renal Disease (MDRD) equation.

In April 2014, the plasma creatinine level rose to $92 \mu \mathrm{mol} / \mathrm{L}$. The medical team first suspected Cisplatin nephrotoxicity, therefore the chemotherapy protocol was changed, and only Pemetrexed and Bevacizumab were maintained from June 2014 at the same doses. However, the kidney function continued to worsen, with a creatinine plasma level of $111 \mu \mathrm{mol} / \mathrm{L}$ in August, and $154 \mu \mathrm{mol} / \mathrm{L}$ in November, corresponding to an eGFR of $42 \mathrm{ml} / \mathrm{min} / 1.73 \mathrm{~m}^{2}$. Chemotherapy sessions were cancelled in December 2014, earlier than expected, when the creatinine plasma level rose to $196 \mu \mathrm{mol} / \mathrm{L}$, corresponding to an eGFR of $24 \mathrm{ml} / \mathrm{min} / 1.73 \mathrm{~m}^{2}$, which then became a contraindication to treatment. At this time, there was no hypertension, proteinuria, hematuria or leukocyturia detected by urine dipstick.

After discontinuation, the creatinine plasma level continued to rise, to $266 \mu \mathrm{mol} / \mathrm{L}$ in January and $297 \mu \mathrm{mol} / \mathrm{L}$ in February 2015. No other treatment was given at this time, especially no non-steroidal antiinflammatory drugs (NSAIDS) or antibiotics.

In February 2015, the patient developed hypertension with no extra-renal clinical signs, and was referred to a nephrologist. The 24-h proteinuria was estimated at $0.7 \mathrm{~g}$. Microscopic hematuria appeared $\left(57.10^{3} / \mathrm{ml}\right)$, without leukocyturia. Blood tests showed thrombopenia $\left(120.10^{3} \mathrm{G} / \mathrm{L}\right)$ and anemia $(8.9 \mathrm{~g} / \mathrm{dL})$, with no laboratory signs of hemolysis or schizocytes (Fig. 1). Antineutrophil cytoplasmic antibodies were absent, as were antinuclear and anti-DNA antibodies. There was no protein activation associated with complement. No gamma globulin abnormalities were seen in plasma protein electrophoresis. The kidney ultrasound showed two kidneys of normal size and shape, well differentiated, with a regular outline and no impediments.

The kidney biopsy, shown in Figs. 2 and 3, revealed acute tubular necrosis. The glomeruli, interstitial compartment and vessels were normal. There were no thrombotic microangiopathic lesions, glomerular or tubular basement membrane deposits, or arteriolar hyalinosis. Immunofluorescence did not show any immune complex deposits. Electron microscopy was not performed.

The renal function did not recover. The patient was discharged and then followed by her medical team closer to home. In December 2015, she had a plasma creatinine level of $266 \mu \mathrm{mol} / \mathrm{L}$. The GFR remained later low (around $17 \mathrm{ml} / \mathrm{min} / 1.73 \mathrm{~m}^{2}$ ) but with no need for dialysis until December 2016.

The anticancer treatment was prolonged in 2015 with 5 cycles of gemcitabine, and a four-month treatmentfree period. In 2016, she received 6 cycles of gemcitabine

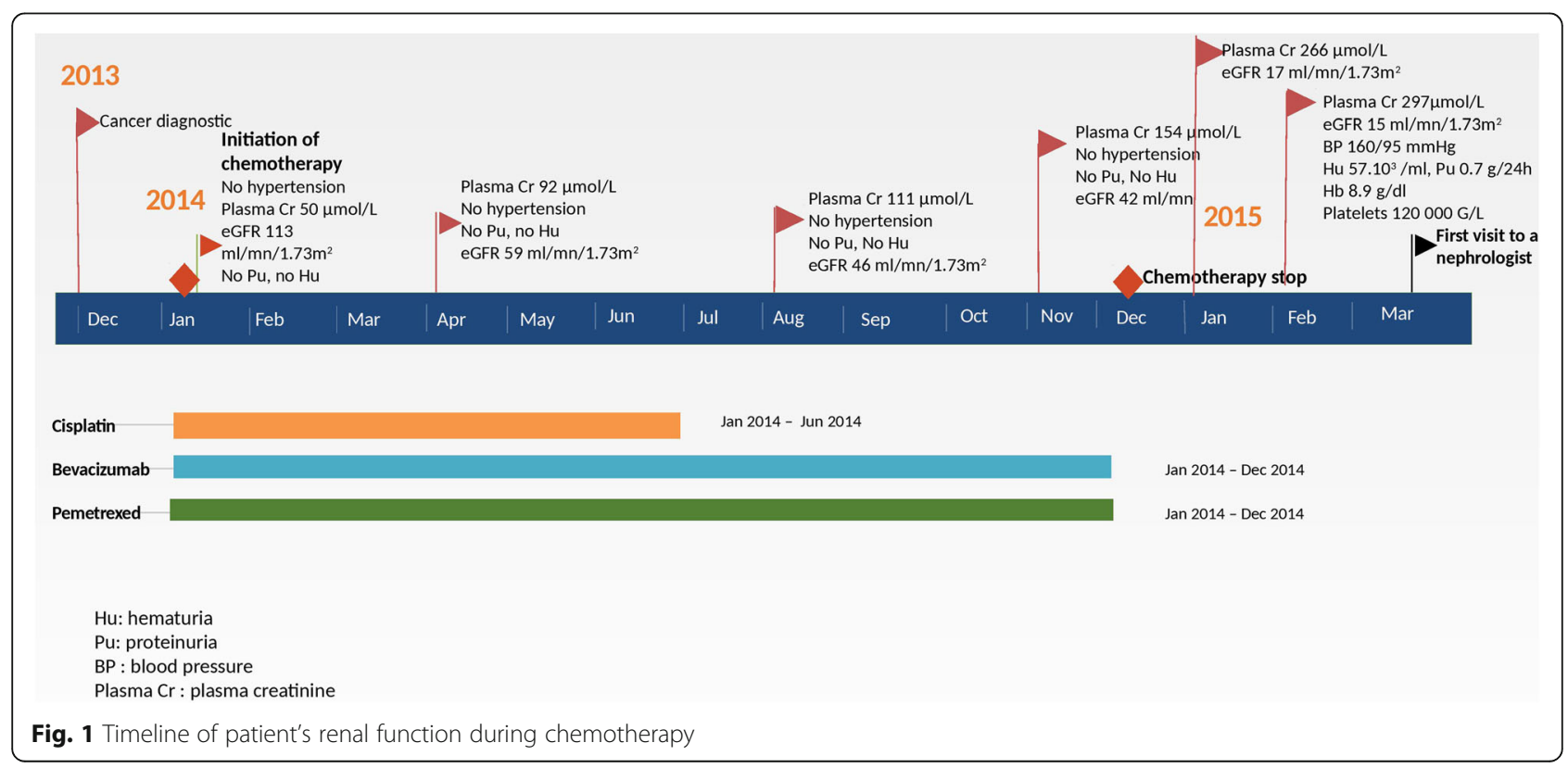




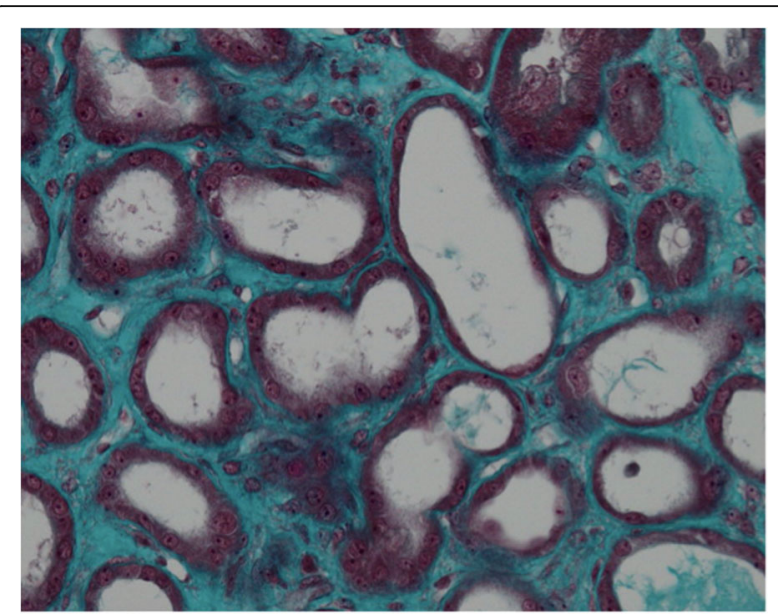

Fig. 2 Kidney biopsy photographs; acute tubular necrosis with tubular cell necrosis and brush border loss. Glomeruli and interstitial

compartment are normal. Immunofluorescence staining was negative

and 6 cycles of paclitaxel. The lung CT scan was stable at the last visit.

\section{Discussion}

This case illustrates rapidly progressing acute renal failure documented by acute tubular necrosis in a patient treated with cisplatin, bevacizumab and pemetrexed.

Cisplatin, a widely used chemotherapeutic agent for lung cancer, has the well-known side effect of nephrotoxicity. Almost $20 \%$ of patients receiving high-dose cisplatin develop acute kidney injury (AKI). One-third of AKI cases occur within a few days of administration, despite appropriate preventive measures (i.e. adequate hydration, dose adjustments) [2, 3]. Cisplatin has been traditionally combined with gemcitabine for metastatic small cell lung cancer. In more recent protocols, a switch from gemcitabine

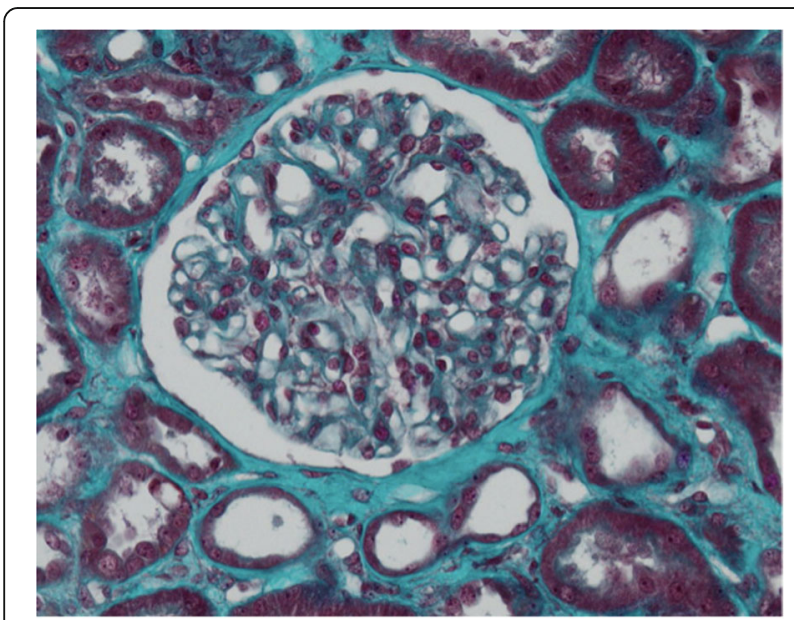

Fig. 3 Kidney biopsy photographs; acute tubular necrosis with tubular cell necrosis and brush border loss. Glomeruli and interstitial compartment are normal. Immunofluorescence staining was negative to pemetrexed, an antifolate cytotoxic agent with lower hematologic toxicity [4], has been used. Pemetrexed is a multitargeted antifolate agent with demonstrated efficacy in pleural mesothelioma and metastatic lung adenocarcinoma [5]. Of note is that it is the first agent to induce improvement in the prognosis of malignant pleural mesothelioma [6]. Pemetrexed inhibits several folate-dependant enzymes involved in purine and pyrimidine synthesis and thus, DNA synthesis. Its main toxicity is linked to vitamin deficiencies (folate and B12) and ranges from nausea/ vomiting and diarrhea to skin rash, mucositis and neutropenia [7]. Pemetrexed is almost exclusively eliminated in the urine. Accumulation may occur in case of pleural or peritoneal effusion, and cumulative side effects may appear. Dialysis does not seem to be efficient for eliminating pemetrexed [8].

As with cisplatin, pemetrexed causes tubular toxicity, whereas gemcitabin and bevacizumab induce vascular defects $[9,10]$. This toxicity seems to appear despite nephroprotective measures. Tubular cell apoptosis seems to be the common feature of pemetrexed toxicity, probably secondary to its accumulation and folate metabolism blockade. One case of nephrogenic diabetes insipidus appearing with pemetrexed has also been reported [11].

The effects of bevacizumab are different. A monoclonal antibody that binds to vascular endothelial growth factor (VEGF) receptors, thus inhibiting its angiogenic effects [12], it is known to induce glomerular changes responsible for proteinuria and some microangiopathy. Tubular injury is very rarely reported with bevacizumab nephrotoxicity but can be seen histologically. Indeed, one article reports five cases of AKI in patients treated with vascular endothelial growth factor inhibitors (four with bevacizumab and one with sorafenib) and highlights the fact that tubular injury with focal necrosis had been seen in all five cases, possibly in addition to thrombotic microangiopathy lesions $[13,14]$.

An increasing number of cases documenting acute kidney insult with pemetrexed have been published $[15,16]$. In every case the authors describe an acute profile of kidney function degradation occurring 1 or 2 weeks after treatment initiation, with further degradation after stopping therapy [17]. In a recent study, around $50 \%$ of patients with maintenance treatment combining pemetrexed and bevacizumab had to stop due to acute kidney injury [1].

If renal toxicity occurs, the causative agent may be difficult to identify. Our case report illustrates the situation of many patients undergoing polychemotherapy treatment. In this case of acute kidney injury, the absence of thrombotic microangiopathy did not support the role of bevacizumab, but the mild proteinuria might have. Cisplatin could have been responsible, since the renal biopsy showed acute tubular necrosis, which is the most frequent 


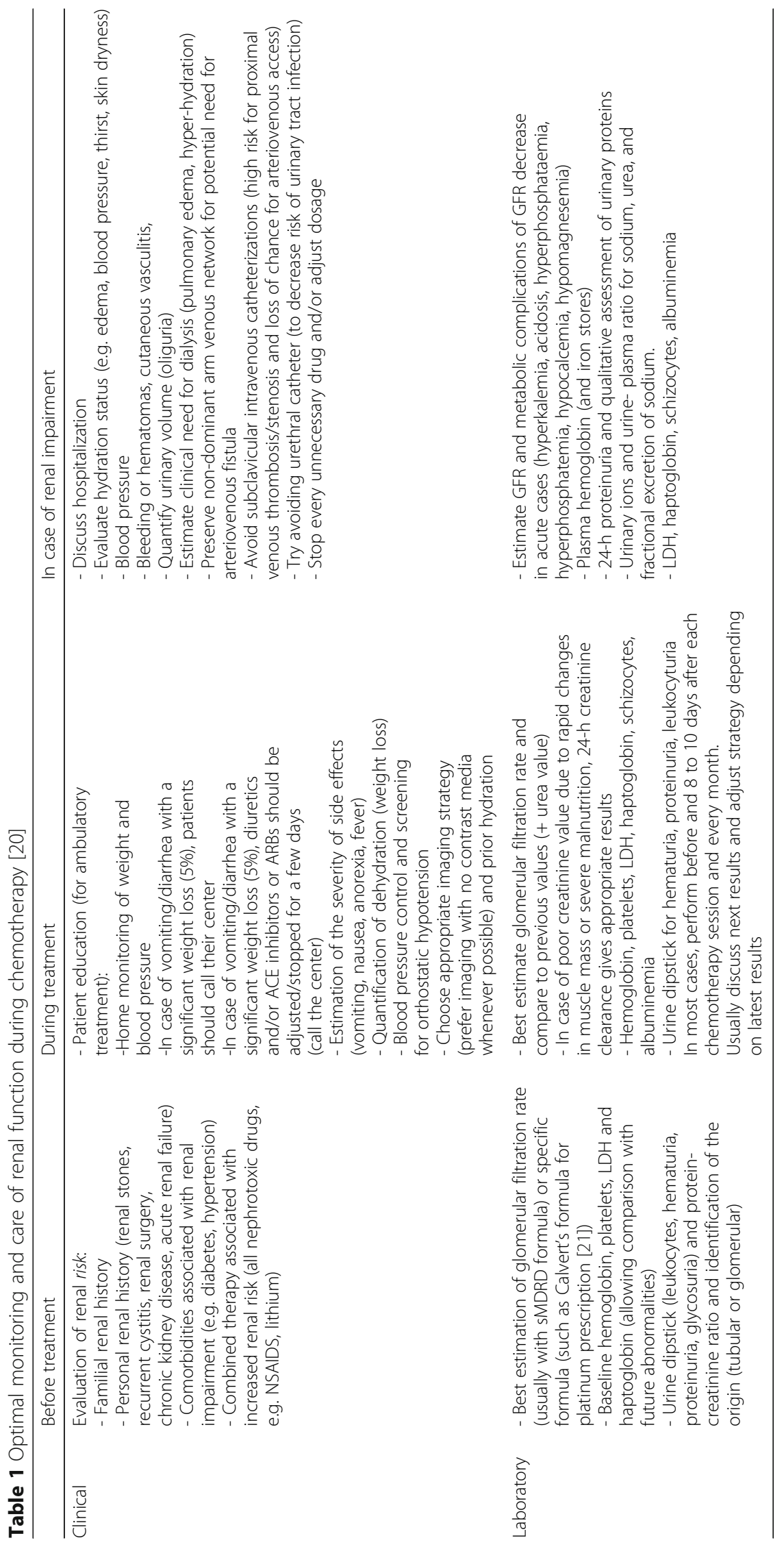




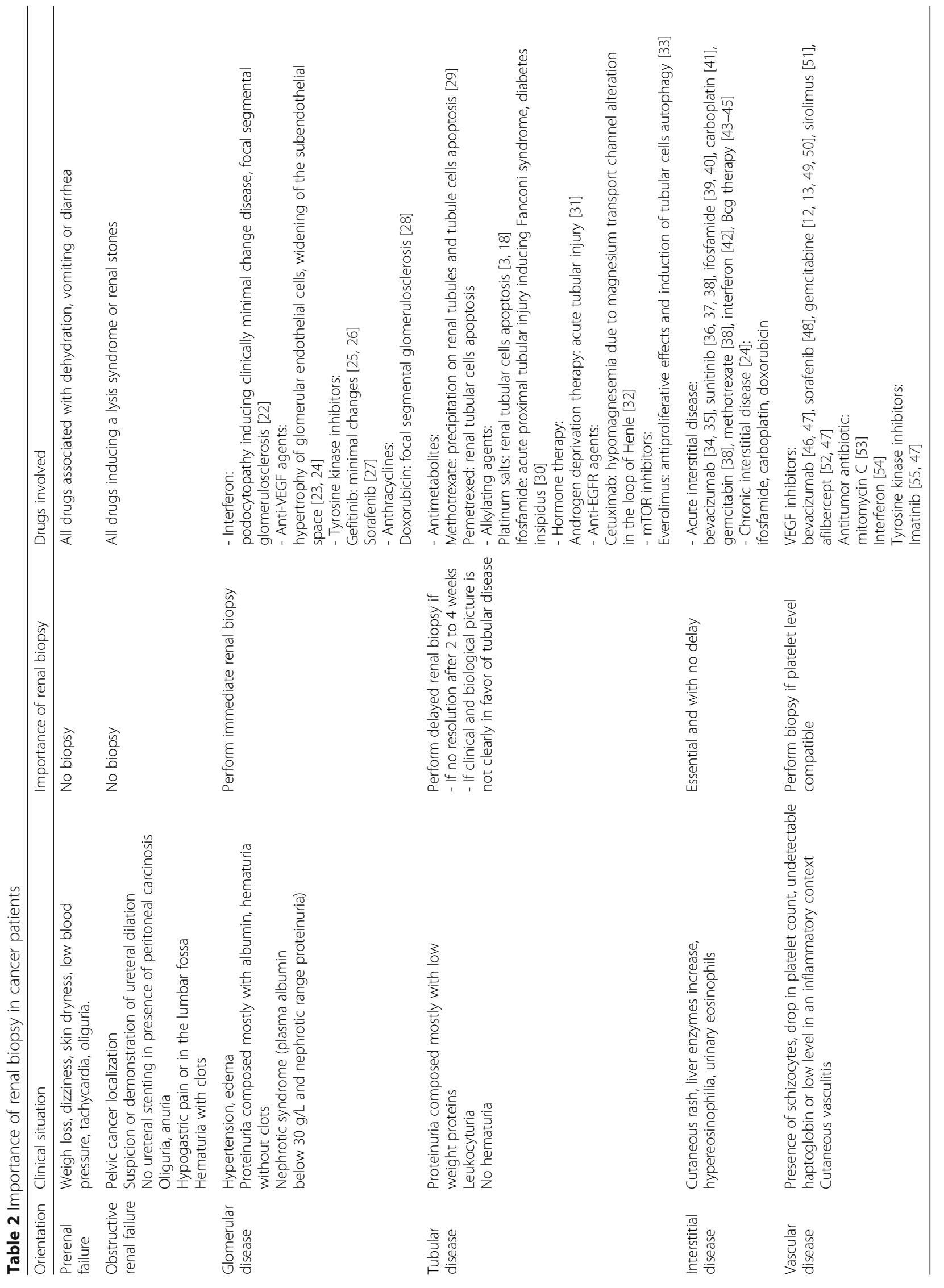


elementary histological lesion expected in cisplatin toxicity; however its reduction or total discontinuation usually allows renal recovery in a few weeks $[2,3,18]$. The deterioration of renal function, despite the elimination of cisplatin months before, tends to rule out the responsibility of platinum salts in our case. Pemetrexed could be the causative agent here, as the renal histology is similar to that seen in other reported cases, and due to the timing and the non-resolution after discontinuation.

If there is no evidence for the cause of acute kidney injury in cases of polychemotherapy, we believe that renal biopsy can help by describing typical, or less typical, lesions. Some types of lesions have been attributed to certain types of chemotherapies (Table 2).

Most articles describe the expected or possible renal side effects during chemotherapy [19]. We suggest that appropriate renal monitoring could allow for early intervention in reducing the consequences of renal toxicity on further treatment (Table 1). Optimal monitoring includes a baseline evaluation to detect patients with preexisting nephropathy and patients at high risk of renal impairment. A few simple questions should be asked at the treatment initiation: is there a history of a renal failure, hematuria or proteinuria? Should we adapt monitoring to this particular patient because of an individual risk score higher than others? Should his/her usual medication be adjusted? Is the patient usually exposed to nephrotoxic drugs (NSAIDs, lithium, etc.) besides cancer treatment?

It is particularly important to monitor clinical and laboratory renal parameters during treatment. For example, significant loss of weight from one cycle to the other (more than $5 \%$ of the initial weight), digestive disorders (diarrhea, vomiting) or hypotension are markers of dehydration and subsequently of the risk of functional renal failure. If creatinine increases, the first questions to be asked are: Is it pre-renal failure due to dehydration? Should I modify the symptomatic treatment? Or start rehydration? Are there factors supporting organic renal failure such as proteinuria, hematuria, leukocyturia, anemia or hemolysis? If the answer to the last question is yes, the chemotherapy should be suspended and the patient immediately referred to a nephrologist.

Being closer to the clinical situation, from a clinical and pragmatic viewpoint, we also share a strategy of action in case of early renal abnormality during treatment (Table 2). Randomized protocols define the usual timelines for laboratory monitoring based on experience with low-risk patients. In "real life", cancer patients may indeed be at very high renal risk. Closer laboratory monitoring may allow a toxic drug to be resumed earlier and the initiation of an early treatment (steroids, plasma exchanges, dialysis, etc.). The list of markers that should be monitored may be tailored depending on the drugs received (glycosuria if Fanconi tubulopathy is expected, for example). In any case, drug dosage adjustment is mandatory if renal function declines. In the event of rapidly progressive renal impairment, hospitalization is highly recommended.

\section{Conclusion}

In conclusion, we would like to highlight the importance of close renal function monitoring in cancer patients. Anticipating side effects through clinical evaluation, laboratory tests and early discussion of renal biopsy may positively influence the outcome of cancer disease by providing the best chances for therapy completion.

\section{Abbreviations \\ ACE: Angiotensin-converting enzyme; AKl: Acute kidney injury; ARBs: Angiotensin II receptor blockers; eGFR: Estimated glomerular filtration rate; GFR: Glomerular filtration rate; MDRD: Modification of diet in renal disease; NSAIDS: Nonsteroidal anti-inflammatory drugs; TNM: Tumor, node, metastasis (classification of malignant tumors); VEGF: Vascular endothelial growth factor}

\section{Acknowledgments}

Not applicable.

\section{Funding}

There is no source of funding to declare.

\section{Availability of data and materials}

Data sharing is not applicable to this article as no datasets were generated or analyzed during the current study.

\section{Authors' contributions}

MA participated in the study design, data collection, and drafted the final manuscript. PR analyzed patients' kidney biopsies and helped define the types of histological toxicities and their corresponding potential causes. MG participated in the data collection and helped to draft the manuscript. GC screened cancer patients and helped define various clinical situations corresponding to different types of nephrotoxicity. PC performed the kidney biopsy and helped define the importance of renal biopsy in cancer patients. LM participated in the data collection and helped to draft the manuscript. GB participated in the study design and helped to draft the manuscript. CIB participated in the study design, data collection, coordination and helped to draft the manuscript. All authors read and approved the final manuscript.

\section{Authors' information}

CARE guidelines/methodology were adhered to.

Ethics approval and consent to participate

Not applicable.

Consent for publication

Written informed consent for publication of her clinical details was obtained from the patient.

\section{Competing interests}

The authors declare that they have no competing interests.

\section{Publisher's Note}

Springer Nature remains neutral with regard to jurisdictional claims in published maps and institutional affiliations.

\section{Author details}

${ }^{1}$ Pitié Salpêtrière Hospital, 75013 Paris, France. ${ }^{2}$ Montargis Dialysis Center, Amilly, France. 
Received: 7 January 2016 Accepted: 26 October 2017 Published online: 16 November 2017

\section{References}

1. Sassier M, Dugué $A E$, Clarisse $B$, et al. Renal insufficiency is the leading cause of double maintenance (bevacizumab and pemetrexed) discontinuation for toxicity to advanced non-small cell lung cancer in real world setting. Lung Cancer. 2015;89(2):161-6.

2. Gi-Su O, So H-S, et al. Cisplatin-induced kidney dysfunction and perspectives on improving treatment strategies. Electrolyte Blood Press. 2014:2:55-65.

3. Ozkok A, Edelstein CL. Physiopathology of cisplatin-induced acute kidney injury. Biomed Res Int, Epub. 2014;

4. Scagliotti GV, Gandara D, et al. Phase III study comparing cisplatin plus gemcitabine with cisplatin plus pemetrexed in chemotherapy-naive patients with advanced-stage non-small-cell lung cancer. J Clin Oncol. 2008;21:3543-51.

5. Rollins KD, Lindley C. Pemetrexed: a multitargeted antifolate. Clin Ther. 2005; 27:1343-82.

6. Budde LS, Hanna NH. Pemetrexed (Alimta): improving outcome in malignant pleural mesothelioma. Expert Rev Anticancer Ther. 2004;4:361-8

7. Socinski MA, Stinchcombe TE, Hayes DN, The evolving role of Pemetrexed (Alimta) in lung cancer. Semin Oncol. 2005:32:16-22.

8. Brandes JC, Grossman SA, Ahmad H. Alteration of Pemetrexed excretion in the presence of acute renal failure and effusions: presentation of a case and review of the literature. Cancer Investig. 2006;24:283-7.

9. Blake-Haskins J, Lechleider R, Kreitman R. Thrombotic microangiopathy with targeted cancer agents. Clin Cancer Res. 2011;17:5858-66.

10. Eremina V, Quaggin S, et al. VEGF inhibition and renal thrombotic microangiopathy. N Engl J Med. 2008;358:1129-36.

11. Vootukuru V, Liew YP, Nally JV Jr. Pemetrexed-induced acute renal failure, nephrogenic diabetes insipidus, and renal tubular acidosis in a patient with non-small cell lung cancer. Med Oncol. 2006:3:419-22.

12. Abbas, et al. Renal toxicities of targeted therapies. Targ Oncol. 2015; epub.

13. Tesarova T. Proteinuria and hypertension in patients treated with inhibitors of the VEGF Signalling pathway - incidence, mechanisms and management. Folia Biol. 2013;59:15-25.

14. Usui, et al. Clinicopathological spectrum of kidney diseases in cancer patients treated with vascular endothelial growth factors inhibitors: a report of 5 cases and review of literature. Hum Pathol. 2014;45:1918-27.

15. Chauvet $\mathrm{S}$, Courbebaisse M, Ronco P, Plaisier E. Pemetrexed induced acute kidney injury leading to chronic kidney disease. Clin Nephrol. 2014;82:402-6.

16. Michels J, Spano JP, Brocheriou I, Deray G, Khayat D, Izzedine H. Acute tubular necrosis and interstitial nephritis during Pemetrexed therapy. Case Rep Oncol. 2009;2:53-6.

17. Izzedine H. Pemetrexed nephrotoxicity. Bull Cancer. 2014;102:190-7.

18. Karasawa T, Steyger PS. An integrated view of cisplatin-induced nephrotoxicity and ototoxicity. Toxicol Lett. 2015;237(3):219-27.

19. Perazella. Renal toxicities of chemotherapeutic agents. Clin J Am Soc Nephrol. 2012:7:1713-21.

20. Shah SR, Tunio SA, Jeoffrey SA, et al. Acute kidney injury recognition and management: a review of the literature and current evidence. Glob J Health Sci. 2015;8(5):49202.

21. Wright JG, Boddy AV, Highley M, Fenwick J, McGill A, Calvert AH. Estimation of glomerular filtration rate in cancer patients. Br J Cancer. 2001;84(4):452-9.

22. Markowitz GS, Nasr SH, Stokes MB, D'Agati VD. Treatment with IFN-alpha, -beta, or -gamma is associated with collapsing focal segmental glomerulosclerosis. Clin J Am Soc Nephrol. 2010;5:607-15.

23. Harakura K, Yokoo T, et al. A case of glomerulopathy associated with the vascular endothelial growth factor inhibitor bevacizumab. Nihon Jinzo Gakkai Shi. 2014:56(5):600-5.

24. Airy M, Raghavan R, Truong LD, Eknoyan G. Tubulointerstitial nephritis and cancer chemotherapy: update on a neglected clinical entity. Nephrol Dial Transplant. 2013 Oct;28(10):2502-9.

25. Maruyama K, Chinda J, Hasebe N, et al. Minimal change nephrotic syndrome associated with gefitinib and a successful switch to erlotinib. Intern Med. 2015:54(7):823-6.

26. Kumasaka R, Nakamura N, Shirato $K$, et al. Side effects of ther- apy: case 1. Nephrotic syndrome associated with gefitinib therapy. J Clin Oncol. 2004;22:2504-5
27. Overkleeft EN, Goldschmeding R, van Reekum F, et al. Nephrotic syndrome caused by the angiogenesis inhibitor sorafenib. Ann Oncol. 2010;21:184-5.

28. Wang YM, Lee $W$, et al. Adriamycin nephropathy in BALB/c mice. Curr Protoc Immunol. 2015;108:1-6.

29. Pitman SW, Parker LM, Tattersall MHN, et al. Clinical trial of highdose methotrexate (NSC-740) with citrovorum factor (NSC-35\%)-Toxicologic and therapeutic observations. Cancer Chemother Rep. 1975;6(suppl):43-9.

30. Perazella MA, Moeckel GW. Nephrotoxicity from chemotherapeutic agents: clinical manifestations, pathobiology, and prevention/therapy. Semin Nephrol. 2010;30:570-81.

31. Lapi F, Azoulay L, Niazi MT, et al. Androgen deprivation therapy and risk of acute kidney injury in patients with pros- tate cancer. JAMA. 2013;310:289-96.

32. Schrag D, Chung KY, Flombaum C, Saltz L. Cetuximab therapy and symptomatic hypomagnesemia. J Natl Cancer Inst. 2005;97:1221-4.

33. Nakagawa S, Masuda S. Involvement of autophagy in the pharmacological effects of the mTOR inhibitor everolimus in acute kidney injury. Eur J Pharmacol. 2012;696(1-3):143-54

34. Lomax AJ, Hill PA, Ashley DM. Case report of interstitial nephritis induced by bevacizumab therapy for glioblastoma multiforme. J Oncol Pharm Pract. 2013;19(4):365-8.

35. Barakat RK, Singh N, Lal R, et al. Interstitial nephritis secondary to bevacizumab treatment in metastatic leiomyosarcoma. Ann Pharmacother. 2007:41:707-10.

36. Winn SK, Ellis S, Savage P, Sampson S, Marsh JE. Biopsy-proven acute interstitial nephritis associated with the tyrosine kinase inhibitor sunitinib: a class effect? Nephrol Dial Transplant. 2009 Feb;24(2):673-5.

37. Khurana A. Allergic interstitial nephritis possibly related to sunitinib use. Am J Geriatr Pharmacother. 2007:5:341-4.

38. Yamamoto A, Naruse S, Ito M, et al. Acute tubulointerstitial ne- phritis associated with long-term gemcitabine therapy. Pancreas. 2007:34:378-9.

39. Hill PA, Prince HM, Power DA. Tubulointerstitial nephritis fol- lowing high dose ifosfamide in three breast cancer patients. Path- ology. 2000;32:166-70.

40. Morland BJ, Mann JR, Milford DV, et al. Ifosfamide nephrotoxi- city in children: histopathological features in two cases. Med Pediatr Oncol. 1996;27:57-61.

41. McDonald BR, Mehta $R L$, et al. Acute renal failure associated with the use of intraperitoneal carboplatin : a report of two cases and review of literature. Am J Med. 1991;90(3):386-91.

42. Averbuch SD, Austin HA III, Sherwin SA, et al. Acute interstitial nephritis with the nephrotic syndrome following recombinant leukocyte a interferon therapy for mycosis fungoides. N Engl J Med. 1984;310:32-5.

43. Kennedy SE, Shrikanth S, Charlesworth JA. Acute granuloma- tous tubulointerstitial nephritis caused by intravesical BCG. Nephrol Dial Transplant. 2006;21:1427-9.

44. Fry A, Saleemi A, Griffiths $M$, et al. Acute renal failure following intravesicle bacille Calmette-Guerin chemotherapy for superficial carcinoma of the bladder. Nephrol Dial Transplant. 2005:20:849-50.

45. Modesto A, Marty L, Suc JM, et al. Renal complications of intra- vesical bacillus Calmette-Guerin therapy. Am J Nephrol. 1991;11:501-4.

46. Tomita M, Ochiai $M$, lehara $\mathrm{N}$, et al. A case of thrombotic microangiopathy with glomerular subendothelial IgA deposition due to bevacizumab. Nihon Jinzo Gakkai Shi. 2014;56(5):612-7.

47. Blake-Haskins JA, Lechleider RJ, Kreitman RJ. Thrombotic Microangiopathy with targeted cancer agents. Nephrology Dialysis Transplantation. 2011; 17(18):5858-66.

48. Usui J, Seshan SV, et al. Clinicopathological spectrum of kidney diseases un cancer patients treated with vascular endothelial growth factor inhibitors: a report of 5 cases and review of literature. Hum Pathol. 2014;45(9):1918-27

49. Richmond J, Gilbar P, Abro E. Gemcitabine induced thrombotic microangiopathy. Intern Med J. 2013;43(11):1240-2.

50. Izzedine $\mathrm{H}$, IsnardBagnis C, Launay-Vacher V, Mercadal L, Tostivint I, Rixe O, et al. Gemcitabine-induced thrombotic microangiopathy: a systematic review. Nephrol Dial Transplant. 2006:21:3038-45.

51. Negrini S, Durrbach A, Becquemont L. Sirolimus-related systemic thrombotic microangiopathy after renal transplantation. Therapie. 2014;69(2):175-7.

52. Izzedine $\mathrm{H}$, Brocheriou I, Deray G, Rixe O. Thrombotic microangiopathy and anti-VEGF agents. Nephrol Dial Transplant. 2007;22(5):22-1481. 
53. Dlott JS, Danielson CF, Blue-Hnidy DE, McCarthy L. Drug-induced thrombotic thrombocytopenic purpura/hemolytic uremic syndrome: a concise review. Ther Apher Dial. 2004;8:102-11.

54. Hunt D, Kavanagh D, Chandran S, et al. Thrombotic mocroangiopathy associated with interferon beta. N Engl J Med. 2014;370(13):1270-1.

55. Al Aly Z, Philocet Ashley JM, Gellens ME, Gonzalez E. Thrombotic

thrombocytopenic Purpura in a patient treated with Imatinib Mesylate: true association or mere coincidence? Am J Kidney Dis. 2005;45:762-8.

Submit your next manuscript to BioMed Central and we will help you at every step:

- We accept pre-submission inquiries

- Our selector tool helps you to find the most relevant journal

- We provide round the clock customer support

- Convenient online submission

- Thorough peer review

- Inclusion in PubMed and all major indexing services

- Maximum visibility for your research

Submit your manuscript at www.biomedcentral.com/submit 